\title{
Pesquisa em Administração Pública: o papel receptor e indutor da Revista de Administração Pública
}

AlKeta PeCl ${ }^{1}$

${ }^{1}$ Fundação Getulio Vargas / Escola Brasileira de Administração Pública e de EMPresas, Rio de Janeiro - RJ, BRASIL

\section{Resumo}

Este artigo discute o papel da Revista de Administração Pública (RAP) no contexto da pesquisa em Administração Pública no Brasil, focando, principalmente, o período entre 2000 e 2010 e apontando tendências a partir de 2015. Para tanto, descreve brevemente o surgimento e a história da RAP ao longo de seus 50 anos, apresenta dados de uma pesquisa que avalia a produção científica acadêmica em Administração Pública no período entre 2000 e 2010 e discute a revista como um espaço receptor e indutor da pesquisa acadêmica de qualidade no campo.

Palavras-chave: Revista de Administracao Pública. Pesquisa em administração pública. Temas e metodologias de pesquisa.

Research in public administration: the reflective and inductive role of the Brazilian Journal of Public Administration

\section{Abstract}

This article discusses the role of the Brazilian Journal of Public Administration (RAP) in public administration research in Brazil. It focuses on the period from 2000 to 2010, and highlights tendencies observed from 2015 on. The article briefly describes the journal's 50-year history, presents data from a research that assesses the scientific and academic production in Public Administration from 2000 to 2010, and discusses the role of RAP as a space to receive and promote quality academic research in the field.

Keywords: Brazilian Journal of Public Administration. Public Administration Research. Research topics and methodologies.

\section{Investigación en Administración Pública: el papel receptor e inductor de la Revista de Administração Pública}

\section{Resumen}

Este artículo discute el papel de la Revista de Administração Pública (RAP) en el contexto de la investigación en Administración Pública en Brasil, enfocando, principalmente, el período 2000-2010 y señalando tendencias a partir de 2015. Para ello, describe brevemente el surgimiento y la trayectoria de la RAP durante sus 50 años, presenta datos de un estudio que evalúa la producción científica académica en Administración Pública en el período 2000-2010 y analiza la revista como un espacio receptor e inductor de la investigación académica de calidad en el campo.

Palabras clave: Revista de Administração Pública. Investigación en Administración Pública. Temas y metodologías de investigación. 


\section{INTRODUÇÃO}

A trajetória da Revista de Administração Pública (RAP) reflete a história do campo de Administração Pública no Brasil. Criada em 1967, junto com o primeiro Mestrado em Administração Pública no país, a RAP materializou a formalização e a sistematização de conhecimento científico acadêmico em uma área em ascensão em vários países do mundo. De fato, a RAP surgiu poucas décadas depois de revistas paradigmáticas internacionais, como a Public Administration ou Public Administration Review, trazendo, no contexto brasileiro, os principais temas e debates de interesse da comunidade acadêmica e prática de Administração Pública.

Desde então, a RAP vem desempenhando um papel histórico em termos de construção de conhecimento em Administração Pública no país. Sua contribuição científica é amplamente reconhecida, o que é corroborado por sua classificação no estrato $\mathrm{A} 2$ não apenas no Qualis da Coordenação de Aperfeiçoamento de Pessoal de Nível Superior (Capes) na área de Administração de Administração Pública e de Empresas, Ciências Contábeis e Turismo, mas também em áreas como Ciência Política e Relações Internacionais e Planejamento Urbano e Regional/Demografia. O prestígio acadêmico da revista se reflete, ainda, nos indexadores nacionais e internacionais nos quais está inserida - Cabell's, Clase, Diadorim, DOAJ, EBSCO, Gale, LatAm-Studies, Latindex, Lilacs, Proquest, Redalyc, Redib, SciELO Brasil, Scopus, Sherpa/Romeo, SPELL - e no expressivo número de acessos que recebe (mais de 15 mil ao mês). Esses são apenas alguns dos indicadores que apontam sua qualidade e seu posicionamento no campo de administração pública.

Refletir sobre a história da RAP demanda uma contemplação aprofundada sobre a dinâmica do campo de Administração Pública, uma vez que, idealmente, o que é veiculado na revista reflete o cerne do conhecimento produzido pela academia de Administração Pública. De modo sintético, neste artigo, apontarei três tensões básicas que sempre se fizeram presentes no conteúdo veiculado na revista: a) a Administração Pública como um campo de relevância prática; b) a Administração Pública como área de conhecimento científico acadêmico; e c) a inserção da produção nacional no campo internacional de Administração Pública. Essas três perspectivas dirigem explícita ou implicitamente o conhecimento produzido em Administração Pública no Brasil. Embora não precisem ser vistas como conflitivas, na prática as perspectivas o são, na medida em que demarcam comunidades institucionais que sustentam o conhecimento que se produz no campo.

Após apresentar brevemente os resultados de uma pesquisa recente sobre produção científica acadêmica em Administração Pública, cujos resultados detalhados são analisados em Peci e Fornazin (2016), termino este artigo com uma reflexão acerca do papel receptor e indutor da RAP no campo de Administração Pública.

\section{ADMINISTRAÇÃO PÚBLICA COMO REFLEXO DA PRÁTICA}

A Administração Pública como prática milenar - cujos resquícios históricos se encontram em qualquer marca civilizatória da humanidade, organizada em busca de segurança, bem-estar e harmonia social - é substancialmente distinta da Administração Pública como campo de conhecimento sistematizado. Esse campo foi responsável por responder intelectualmente aos desafios impostos pela consolidação da burocracia pública, em vários contextos nacionais caracterizados por um papel de Estado em expansão, desde o final do século XIX. É a partir desse período que a Administração Pública começa a se voltar para a separação entre Política e Administração e para a compreensão das tensões resultantes da sobreposição dessa instituição com tendências autoritárias (a burocracia) à ideia, então revolucionária, da soberania popular e da democracia (LYNN JR., 2005; ROOSENBLOOM, 1983).

Ao longo de décadas, as "tensões" inerentes ao campo de Administração Pública, especificamente sua relação com a política e democracia, têm inspirado uma fértil produção científica acadêmica que se distingue em seus interesses de pesquisa de outras áreas do conhecimento, como Ciência Política, Administração de Empresas, Sociologia, entre tantos outras, mas, ao mesmo tempo, também se aproxima dessas comunidades acadêmicas na tentativa de legitimar um campo de conhecimento em constante busca de autoridade científica. A proliferação de programas acadêmicos e de revistas científicas e as inúmeras tentativas de "autoavaliação" que objetivam validar o caráter "científico" dessa produção intelectual são apenas alguns indícios dessa busca de legitimidade.

Ao invés de refletir uma consolidação do conhecimento em Administração Pública em torno dessas questões-chave do campo, os primeiros anos de estabelecimento do campo acadêmico da Administração Pública refletiram certa dificuldade de delimitação entre o campo acadêmico e o campo da prática (e isso não parece ser exclusividade do contexto brasileiro). 
De acordo com Pacheco (2003), a análise dos artigos de Administração Pública publicados indica o vale-tudo e a rápida adesão a modismos temáticos, bem como análises apaixonadamente ideológicas. A autora compartilha as análises de Machado-daSilva, Amboni e Cunha (1989) e Souza (1998), que identificaram várias fragilidades dos trabalhos de Administração Pública relacionadas com baixa utilização da literatura estrangeira atualizada, predomínio de metodologias pouco elaboradas e prevalência do enfoque prescritivo em detrimento do analítico.

Os artigos que efetivamente conseguem ser publicados em periódicos da área até essas primeiras avaliações do campo (final dos anos 1990) são, geralmente, "grandes ensaios generalizantes ou conceituais", que abordam múltiplos temas e assumem, predominantemente, a forma de estudos de caso setoriais. Para Pacheco (2003), essas problemáticas podem ser atribuídas às características da comunidade de pesquisa em Administração Pública, uma comunidade pequena e autorreferida, ligada a poucos programas de pós-graduação stricto sensu, geralmente justapostos aos programas de business no sistema de pós-graduação.

Um dos trabalhos mais importantes que buscou avaliar o conteúdo da produção científica brasileira em Administração Pública, particularmente o veiculado na RAP e o de Mezzomo e Laporta (1994). Os autores analisaram a evolução do campo da Administração Pública no Brasil a partir dos 721 artigos publicados na RAP desde sua criação, em 1967, até o ano de 1992. Com base em Kuhn (2009) e em autores norte-americanos, como Golembiewski (1977) e Henry (1975), a autora faz uma análise paradigmática da evolução do conhecimento em Administração Pública no Brasil, no período entre 1900 e 1992, identificando quatro paradigmas principais: Administração Pública como ciência jurídica; Administração Pública como ciência administrativa; Administração Pública como ciência política; e Administração Pública como administração pública. A análise paradigmática é aliada a uma perspectiva histórica, de modo que cada um dos paradigmas é relacionado a determinado período histórico, embora tal divisão não implique uma rigorosa divisão dos paradigmas, que se fazem presentes simultaneamente, com maior ou menor fôlego, em determinados períodos.

Fica claro, nas análises acima citadas, que o que é produzido em Administração Pública reflete a evolução do campo da prática. Em outras palavras, temas, ideias e dinâmicas que permeiam a história de administração pública no Brasil são, de certo modo, incorporadas na agenda de pesquisa (ou ensaios) produzidos pelo campo acadêmico. Faltam consistência, profundidade e fôlego às pesquisas, cuja agenda é pautada pela agenda do governo.

Com o crescimento quantitativo de programas acadêmicos em Administração Pública, assim como a partir da pressão avaliativa de entidades como a Capes, a demarcação academia $\times$ prática começa a se tornar mais nítida. Tal demarcação se faz presente, principalmente, em uma gradual sofisticação dos métodos de pesquisa. Uma análise dos trabalhos publicados nos Encontros da Associação Nacional dos Programas de Pós-Graduação em Administração (EnANPAD) ao longo do período 2000-2005 encontra maior número de trabalhos teórico-empíricos (76,1\%) em comparação com períodos anteriores. Entretanto, a análise também identifica um predomínio do estudo de caso $(55,7 \%)$ como estratégia de pesquisa, ao lado do certo crescimento do uso de métodos quantitativos. Este estudo também identifica o papel de instituições de origem na produção em Administração Pública, especificando que 5 instituições, com destaque para a Fundação Getulio Vargas do Rio de Janeiro (FGV-RJ) e a Fundação Getulio Vargas de São Paulo (FGV-SP), que respondem por aproximadamente 50\% dos artigos publicados nesse período (HOCAYEN-DA-SILVA, ROSSONI e FERREIRA JUNIOR, 2008b).

\section{PRODUÇÃo CONTEMPORANEA EM ADMINISTRAÇÃo PÚBLICA NO BRASIL}

Para compreendermos, de modo comparativo, como o conhecimento produzido em Administração Pública no país se distingue das tendências citadas, apresento dados de uma pesquisa comparativa (cf. PECI e FORNAZIN, 2016; PECI, RIBEIRO, RODRIGUES et al., 2011) que avaliou a orientação paradigmática cognitiva dos trabalhos publicados em selecionados periódicos brasileiros, no período 2000-2010, as opções metodológicas utilizadas pelos autores brasileiros que publicam em Administração Pública e a composição institucional da produção científica acadêmica em Administração Pública, verificando quais programas de pós-graduação contribuem para o campo e quais filiações autorais predominam na publicação.

Além da RAP foram incluídos nessa análise os principais periódicos voltados integral ou parcialmente à produção científica acadêmica em Administração Pública, especificamente: Brazilian Administration Review (BAR); Cadernos EBAPE.BR; Revista de Administração Contemporânea (RAC); Revista de Administração Contemporânea Eletrônica (RAC-Eletrônica); e Revista de Administração de Empresas (RAE). Todos os artigos identificados como Administração Pública - um total de 592 - foram submetidos a técnicas de análise de conteúdo (KRIPPENDORFF, 2004) e estatística descritiva (uni ou bivariada). 
O estudo indica que a RAP continua o principal veículo no campo da Administração Pública no país. De fato, ao todo, 421 artigos considerados pertencentes a esse campo, dos 592 analisados, foram publicados na RAP. Sua participação relativa vem diminuindo ao longo dos anos, em grande parte devido ao crescimento do periódico Cadernos EBAPE.BR. Embora o numero de veículos acadêmicos brasileiros tenha crescido substancialmente no período analisado, os demais veículos corresponderam, somados, a menos de $10 \%$ da produção no período. O Gráfico 1 aponta, nas colunas, no eixo à esquerda, as tendências da participação relativa dos veículos de 2000 a 2010, evidenciando o papel da RAP.

\section{Gráfico 1}

\section{Participação relativa das revistas na produção de Administração Pública}

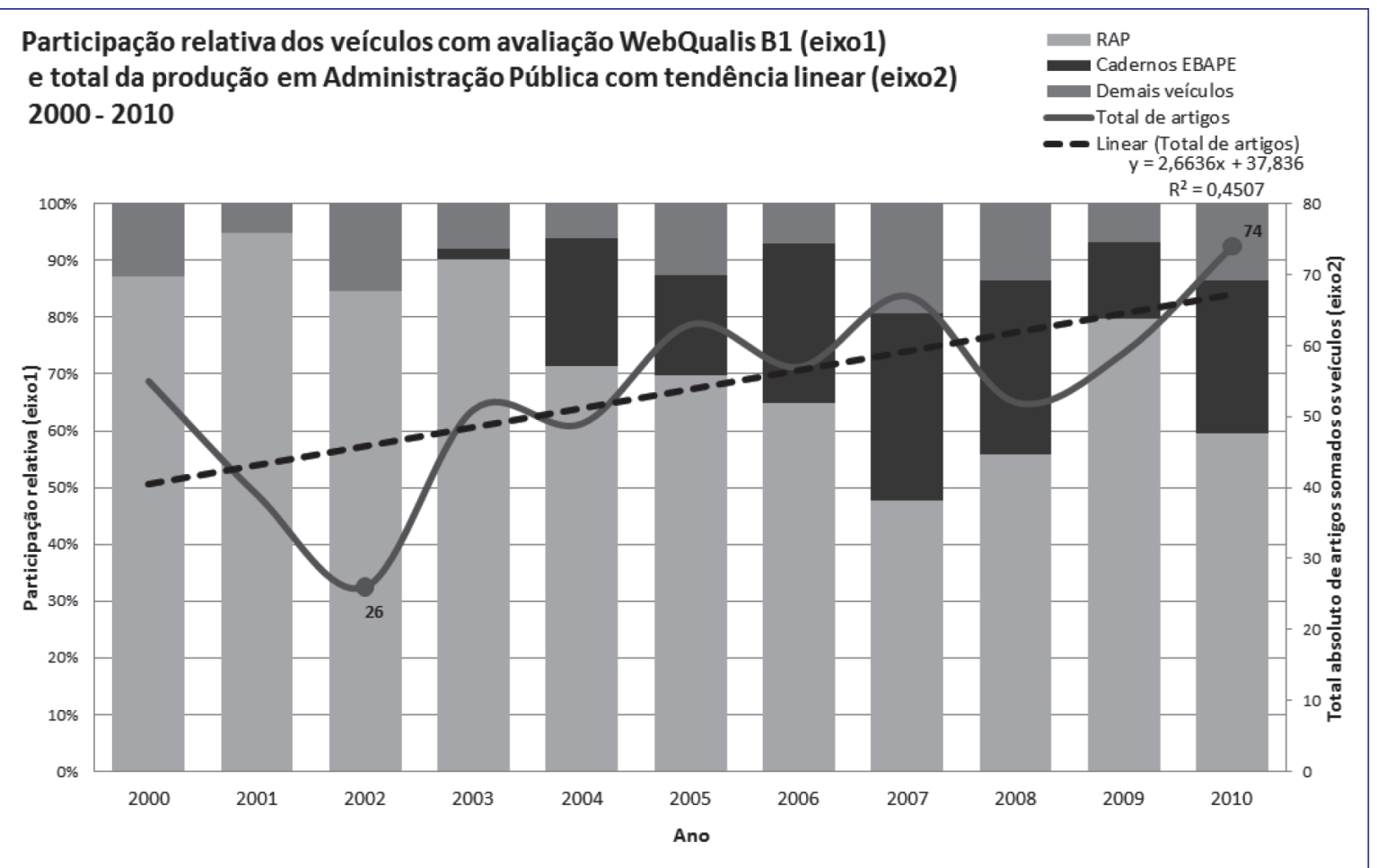

Fonte: Microdados FGV EBAPE (2011).

A pesquisa também identificou que grande quantidade de publicações são orientadas pelo paradigma da Governança (28,4\%) e do Gerencialismo (29,6\%). Os trabalhos de governança refletem a atual perspectiva da Administração Pública brasileira após a reforma administrativa de 1995 se referindo a temas como colaboração e parcerias no setor publico, regulação e agencias reguladoras, entre outras. Paralelamente, os trabalhos orientados pelo Gerencialismo refletem um foco natural e persistente da pesquisa em Administração Pública, a racionalização, via melhoria da eficiência, eficácia, efetividade ou qualidade operacional e organizacional.

Em termos de orientação metodológica, dos 592 trabalhos analisados, 355 artigos (60\%) são empíricos e 237 artigos (40\%) são teóricos. Dentre esses trabalhos empíricos, ainda predominam os de orientação metodológica qualitativa (76\%). De acordo com Lan e Anders (2000), nos Estados Unidos da América (EUA), antes dos anos 2000, 58,7\% dos artigos publicados tinham orientação metodológica qualitativa, sendo, entretanto, a metodologia quantitativa uma corrente bastante representativa (40,8\%). No Brasil, os trabalhos de orientação quantitativa ainda somam apenas 19,4\% do total de publicações. A matriz metodológica brasileira na área de Administração Pública continua sendo de cunho qualitativo.

Entretanto, a partir de 2006, essa tendência se altera e a quantidade de trabalhos quantitativos começa a crescer. Este dado, somado a observação atual de crescentes submissões de pesquisas de natureza quantitativa na RAP, indica uma clara tendência a favor de metodologias quantitativas no campo. O estudo também identificou que ainda predominam fraquezas metodológicas significativas nos trabalhos analisados, ilustrados pela existência de "levantamento e "casos ilustrativos; pela falta de especificação, ainda presente em vários trabalhos, nos instrumentos de coleta e de analise de dados, e pela baixa representatividade de métodos estatísticos mais que foram utilizados em 10,1\% dos trabalhos. 
Tabela 1

\section{Frequências dos métodos de análise de dados}

\begin{tabular}{cc}
\hline Metodo de análise de dados & Frequência \\
\hline Análise de conteúdo & $20,5 \%$ \\
Análise de discurso & $3,6 \%$ \\
Estatística descritiva & $14,7 \%$ \\
Estatísticas intermediárias & $3,6 \%$ \\
Não especificado & $47,5 \%$ \\
Estatísticas avançadas & $10,1 \%$ \\
\hline
\end{tabular}

Fonte: Elaborada pela autora.

Se a produção de alto nível de 2000 a 2010 se concentrou na RAP, o mesmo ocorreu em relação à filiação institucional dos primeiros autores. A produção dos autores vinculados às instituições é apresentada na Tabela 2. Há poucas instituições que publicam muito e muitas instituições que publicam pouco. Do total de 145 instituições registradas como sendo o vínculo principal do primeiro autor, 109 (75\%) têm apenas até 2 trabalhos publicados. Os artigos de autores dessas 109 instituições correspondem a $21 \%$ dos trabalhos publicados. Por outro lado, as 14 instituições ( $10 \%$ do total) que publicaram mais de 10 artigos correspondem a $62 \%$ da produção. As 4 primeiras instituições no ranking de número de artigos publicados são as únicas a possuir mais de 30 artigos publicados e correspondem, somadas, a $33 \%$ da produção ${ }^{1}$.

Tabela 2

Frequência da produção de autores associados às instituições

\begin{tabular}{ccccc}
\hline Posição & Instituição & Artigos & $\begin{array}{c}\text { Freq. relativa } \\
(\%)\end{array}$ & $\begin{array}{c}\text { Freq. relativa } \\
\text { acumulada (\%) }\end{array}$ \\
\hline 1 & EBAPE/FGV & 78 & $13 \%$ & $13 \%$ \\
2 & EAESP/FGV & 49 & $8 \%$ & $22 \%$ \\
3 & UFBA & 34 & $6 \%$ & $28 \%$ \\
4 & PUC/RJ & 31 & $5 \%$ & $33 \%$ \\
5 & UFMG & 25 & $4 \%$ & $37 \%$ \\
6 & USP & 22 & $4 \%$ & $41 \%$ \\
7 & ENSP/Fiocruz & 20 & $3 \%$ & $44 \%$ \\
8 & UFRGS & 19 & $3 \%$ & $48 \%$ \\
9 & UnB & 18 & $3 \%$ & $51 \%$ \\
10 & UFRN & 15 & $3 \%$ & $53 \%$ \\
11 & UFPE & 15 & $3 \%$ & $56 \%$ \\
12 & UFSC & 14 & $2 \%$ & $58 \%$ \\
13 & PUC/SP & 13 & $2 \%$ & $60 \%$ \\
14 & UFRJ & 11 & $2 \%$ & $62 \%$ \\
De 15 a 145 14101 instituições & 221 & $38 \%$ & $100 \%$ \\
\hline 145 instituições & 585 & & \\
\hline
\end{tabular}

Fonte: Elaborada pela autora.

${ }^{1}$ Percentuais correspondentes ao total de 585 artigos, onde foi possível identificar a filiação do primeiro. Em 7 artigos essa identificação não foi possível. 
A Tabela 2 corrobora os resultados de Hocayen da Silva, Rossoni e Ferreira Júnior (2008a), situando a Escola Brasileira de Administração Pública e de Empresas da Fundação Getulio Vargas (FGV EBAPE) e a Escola de Administração de Empresas de São Paulo (FGV EAESP) como as principais instituições publicadoras em Administração Pública. De 2000 a 2010, essas 2 instituições foram responsáveis por praticamente $1 / 4$ dos artigos em Administração Pública publicados nos veículos com WebQualis B1 ou superior. Há, entre as 14 principais instituições, com mais de 10 artigos publicados, representantes das regiões Sudeste, Sul, Nordeste e 1 da região Centro-Oeste. Não há representantes da região Norte.

Observando as tendências mais recentes da RAP, destacamos também a pesquisa de Da Silva Smolski, Dalcin, Visentini et al. (2017) sobre os artigos veiculados na revista no período 2003-2016. Os autores indicam que:

a) As contribuições veiculadas na RAP deixaram de ser exclusividade de uma área especifica do conhecimento, geralmente induzida pela guarda-chuva das áreas Capes. De fato, segundo os autores, ofocus Ciências Administrativas continua perdendo participação nas publicações totais (70,2\% para 56,1\% neste estudo), seguido por Sociologia (6,0\% para 4,3\%). Destacam-se os demais campos de estudo (Outros: 7,2\% para 14,4\%) e Ciências Econômicas (5,5\% para 10,8\%), que aumentaram sua participação na revista em relação ao estudo anterior.

b) Em termos de abordagem metodológica, a predominância é de produções do tipo Aplicadas - 60,9\% dos artigos. É expressiva a participação de artigos Qualitativos (76,4\%), seguidos por aqueles da tipificação Mista (13,4\%) e dos Quantitativos (10,2\%). Novamente, também vale observar que os trabalhos quantitativos são os que mais demonstram tendência de crescimento.

A pesquisa analisa, ainda, outros aspectos institucionais das publicações, a participação crescente (ainda menor em termos absolutos) de mulheres, evidenciando o papel das coautorias. Os pesquisadores indicam que trabalhos em coautoria estão relacionados à titulação do pesquisador e a estudos de natureza quantitativa e aplicada, os quais, de modo geral, demandam mais dados ou domínio de diferentes técnicas de análise.

\section{As Fragilidades do Conhecimento Produzido em Administração Pública são Exclusividade Brasileira?}

O campo norte-americano de produção científica acadêmica em Administração Pública compartilha com o contexto brasileiro a sistemática tentativa de autoavaliação. Entretanto, enquanto o processo de autoavaliação da produção científica acadêmica brasileira em Administração Pública se consolida a partir de 1989, com os trabalhos de Machado-da-Silva, Amboni e Cunha (1989), no contexto norte-americano esses trabalhos surgem a partir da década de 1970 (HENRY, 1975), fortemente influenciados pela abordagem paradigmática de Thomas Kuhn (2009).

A avaliação da produção científica acadêmica em Administração Pública, no contexto norte-americano, também caracteriza-se por várias polêmicas e discordâncias. De modo geral, as avaliações diagnosticam a falta de rigor metodológico dos artigos e das dissertações publicadas, assim como o foco em problemas e questões relacionadas à prática profissional ao invés de desenvolvimento ou teste de proposições teóricas, ou seja, uma orientação prescritiva das publicações (BINGHAM e BOWEN, 1994; BOX, 1992; PERRY e KRAEMER, 1986; STALLINGS e FERRIS, 1988). Para outros, essa avaliação é exagerada, porque se parte de pressupostos positivistas quantitativos, desvalorizando as metodologias alternativas, de natureza mais interpretativa (McCurdy e CLEARY, 1984). Entretanto, as avaliações reconhecem que mesmo as metodologias alternativas têm sido adotadas de modo superficial, sem explicitar os pressupostos epistemológicos e ontológicos que lhes servem de base (WHITE, 1986).

O conteúdo da produção científica acadêmica em Administração Pública tem atraído mais o interesse das avaliações norteamericanas, marcando uma diferença importante com as avaliações empreendidas no contexto brasileiro. Os autores identificam que a produção em Administração Pública é caracterizada por certa dificuldade em identificar questões centrais de importância para o campo. Perry e Kraemer (1986) identificaram duas áreas de estudo como particularmente relevantes para a Administração Pública nos EUA, especificamente: a) o estudo das características que distinguem a Administração Pública de outras administrações; e b) a interface do sistema administrativo com o político. Desse modo, a eterna tensão entre Política e Administração é considerada central ao estudo de Administração Pública. Bingham e Bowen (1994) verificam que os artigos publicados na Public Administration Review se centram em torno de número de temas menor do que o dos publicados em livros didáticos de Administração Pública, enquanto Wright (2011) identifica que a pesquisa em Administração Pública é isolada das 3 disciplinas fundamentais da área - Direito, Administração Geral e Ciência Política - não citando frequentemente trabalhos originados desses campos do conhecimento. 
Entretanto, boa parte das avaliações conclui que não existem fundamentos teóricos centrais ao campo de Administração Pública e, por essa razão, qualifica como "crise intelectual" o estudo acadêmico da Administração Pública (MILLER e JAJA, 2005). De fato, a diversidade de tópicos e temas abordados - tal como identificado por Pacheco (2003) no Brasil - relaciona-se à natureza de Administração Pública, permeada por múltiplos tópicos de interesse (WHITE, 1986).

As avaliações iniciais, de natureza mais crítica, estão cedendo espaço para avaliações mais pluralistas da produção em Administração Pública. Miller e Jaja (2005), ao avaliar os simpósios publicados em 5 periódicos reconhecidos do campo, diagnosticam a infusão de métodos qualitativos, a ausência de consenso metodológico e a falta de fundamentos teóricos, mas consideram essa "tensão intelectual" positiva e vital para a dinâmica do campo de Administração Pública.

Aspectos institucionais e autorais também têm sido constantemente objeto de avaliação da produção norte-americana em Administração Pública. Vários aspectos, como perfil institucional e professional dos autores (LAN e ANDERS, 2000), minorias e outras representações em publicações da área (KELLOUGH e PITTS, 2005) ou a relação com os practitioners (STREIB, SLOTKIN e RIVERA, 2001) foram alguns dos objetos dessa análise.

\section{O tecido institucional como obstáculo à pesquisa acadêmica brasileira}

Nossa pesquisa revela algumas semelhanças com o contexto norte-americano, no sentido de que a pesquisa em Administração Pública no país compartilha algumas orientações paradigmáticas cognitivas (gerencialismo, política, etc.) e também predominam metodologias qualitativas e estudos de caso. Em outras palavras, os temas privilegiados pelos pesquisadores dos dois contextos apresentam semelhança e indicam que existe, sim, uma fertilização conceitual entre vários contextos nacionais.

Entretanto, diferente das análises realizadas no contexto norte-americano, acreditamos que existem fatores que diferenciam substancialmente a pesquisa brasileira, entre as quais, destacamos:

a) Não existe um tecido institucional sólido, composto por vários programas de pós-graduação e múltiplas autorias (e, consequentemente, de contribuições etc.);

b) Ainda existe considerável fraqueza metodológica, que é mais bem percebida quando se faz uma análise mais detalhada das estratégias metodológicas e se percebe que as metodologias não são qualificadas nem em termos de instrumentos e menos em termos de técnicas de análise (demonstrando fraca vinculação com o referencial teórico do trabalho, o que induz a fraquezas teóricas).

Entre estes fatores diferenciais, o mais importante e, no nosso entender, o que mais influencia a qualidade da pesquisa em administração publica no pais tem a ver com o tecido institucional estabelecido nos dois contextos. Como observado, diferente do contexto norte-americano onde há uma forte comunidade acadêmica, no Brasil algumas poucas instituições são responsáveis pela maioria da produção em Administração Pública.

Tudo indica que ao passo que as ideias "viajam" de um contexto para outro, representadas em maior ou menor grau pela orientação paradigmática cognitiva, a base material, representada por um fraco tecido institucional e a falta de internalização da maestria de puzzle solving (KUHN, 2009) ainda são obstáculos para a produção de pesquisa qualificada em Administração Pública.

Alguns problemas levantados em termos de teorização e maturidade metodológica não são típicos brasileiros. 0 vale-tudo temático parece estar presente nos dois contextos pesquisados e, de fato, pode ser relacionado ao caráter muito prático da área de Administração Pública. Por exemplo, muitos dos pesquisadores, norte-americanos ou brasileiros devem trabalhar em projetos de consultoria de governo.

Além disso, a pesquisa indica que a insatisfação com a qualidade metodológica está presente nos dois campos e pode ser vista à luz de sua natureza orientada pela prática de Administração Pública. Talvez a pesquisa publicada em Administração Pública seja mais relevante porque responde aos anseios dinâmicos da prática, mas menos apta a ser rotulada como "cientifica" e, talvez, os pesquisadores brasileiros devam saber lidar melhor com essa característica flutuante de seu campo, encontrando formas de aumentar a relevância, alinhando maior rigor acadêmico, saindo dos círculos institucionais autorreferentes, como diagnosticado por Pacheco (2003), e estabelecendo pontes de conversação com outros campos acadêmicos (Estudos Organizacionais, Ciência Política ou Direito). 


\section{O PAPEL RECEPTOR E INDUTOR DA REVISTA DE ADMINISTRAÇÃO PÚBLICA}

É natural que uma revista histórica para o campo de Administração Pública no país, como a RAP, reflita, em boa medida, a natureza desse conhecimento produzido desde o surgimento dos primeiros programas acadêmicos no país, nos anos 1960. Como destaco em outras análises, e, por vezes, superando estes condicionantes institucionais, nesses anos de existência, a RAP "publicou alguns dos mais importantes trabalhos acadêmicos sobre Administração Pública e [T]eoria das [O]rganizações produzidos em nosso país" (MARTINS, 2007, p. 54), alguns dos quais se tornaram marcos do pensamento administrativo brasileiro, como exemplificado pela contribuição de Alberto Guerreiro Ramos, Paulo Roberto Motta, Ana Maria Campos, entre tantos outros.

Na editoria da RAP desde 2015, assumi como objetivo principal da revista sua crescente internacionalização. A partir do primeiro número de 2017, a revista passou a ser publicada em inglês e português. Essa mudança materializou o objetivo da revista de consolidar-se como um periódico acadêmico de Administração Pública brasileiro que busca expandir sua contribuição científica acadêmica além das fronteiras nacionais. Acreditando no papel indutor da RAP, realizamos, ao longo destes anos, uma serie de seminários voltados para pesquisadores brasileiros contando com a cooperação dos editores das revistas mais reconhecidas intrnacionais do nosso campo, como o JPART (Journal of Public Administration Research and Theory), PAR (Public Administration Review) e Public Administration, entre outros parceiros latino-americanos.

Muda a forma, buscando, acima de tudo, qualificar ainda mais o conteúdo das contribuições veiculadas na RAP, publicando artigos que trazem reforços substanciais para temas transversais de Administração Pública, no contexto nacional e internacional.

Entretanto, a qualidade não é um dos objetivos dos mais simples de alcançar. A peculiaridade dos artigos que cada número da RAP apresenta ao leitor depende de um conjunto de esforços de uma comunidade por vezes invisível de pareceristas, editores adjuntos, autores e leitores que contribuem sistematicamente com a revista. A qualidade também depende de uma mudança cultural de todos os envolvidos, respeitando o processualismo da blind review, encaminhando pareceres detalhados e construtivos que busquem desenvolver o potencial de um manuscrito submetido à revista e respondendo com revisões substanciais do trabalho a esses pareceres, evitando o "faz de conta": todo esforço em busca de um produto final mais sólido que contribui para o saber em Administração Pública.

Não precisamos de mais artigos publicados; hoje, o Brasil conta com mais de 100 revistas acadêmicas, um número que, por si, já muito diz a respeito da busca desenfreada por publicações. Nossa estratégia de internacionalização busca, acima de tudo, melhorar a qualidade dos artigos aprovados, incentivando um gradual processo de mudança cultural em busca de maior qualificação.

As mudanças já começam a ser sentidas. Em primeiro lugar, cresceu o número de trabalhos submetidos em outras línguas e por autores internacionais. Até dezembro de 2017, o número de artigos submetidos em inglês saltou para 60 trabalhos e o número de artigos submetidos em espanhol subiu para 14 trabalhos, totalizando $21,7 \%$ do total de trabalhos submetidos à revista. O crescimento é expressivo quando comparado ao ano de 2011, quando a RAP recebeu apenas 3 trabalhos em inglês e espanhol ( $1 \%$ do total de artigos submetidos).

Mais importante, a revista conseguiu atrair uma comunidade cada vez mais internacional de autores: 48 artigos submetidos foram de autores localizados fora do Brasil, representando 17 países. Os dados demonstram que a RAP começa a se estabelecer como um periódico importante para algumas regiões esperadas: Portugal e América Latina. Idioma, mas, acima de tudo, fatores institucionais e culturais, explicam tal proximidade. Esperemos que eles se traduzam na consolidação de redes de pesquisa que contribuam para o fortalecimento da área de Administração Pública.

Finalizando, hoje, a RAP busca expandir as fronteiras geográficas na produção de conhecimento de ponta em Administração Pública, guiada pela premissa de que a pesquisa de qualidade surge de redes consolidadas de pesquisa, estruturadas em torno de temas nacionais e internacionais. 0 produto esperado dessas redes - a pesquisa de qualidade - é o que a revista busca induzir. Essa qualidade também é a maior contribuição que uma revista como a RAP pode proporcionar para a melhoria da Administração Pública como prática. 


\section{REFERÊNCIAS}

BINGHAM, R. D.; BOWEN, W. M. “Mainstream” public administration over time: a topical content analysis of Public Administration Review. Public Administration Review, v. 54, n. 2, p. 204-208, 1994.

BOX, R. C. An examination of the debate over research in public administration. Public Administration Review, v. 52, n. 1, p. 620669, 1992.

DA SILVA SMOLSKI, F. M. Análise do perfil da produção científica da Revista de Administração Pública (RAP) no período 2003-16. Revista de Administração Pública, v. 51, n. 6, p. 1139-1163, 2017.

GOLEMBIEWSKI, R. T. Public administration as a developing discipline. New York: Decker, 1977.

HENRY, N. Paradigms of public administration. Public Administration Review, n. 35, p. 378-86, 1975.

HOCAYEN-DA-SILVA, A. J.; ROSSONI, L.; FERREIRA JUNIOR, I. Administração pública e gestão social: a produção científica brasileira entre 2000 e 2005. Revista de Administração Pública, v. 42, n. 4, p. $655-680,2008$ a.

HOCAYEN-DA-SILVA, A. J.; ROSSONI, L.; FERREIRA JUNIOR, I. Aspectos estruturais da cooperação entre pesquisadores no campo de administração pública e gestão social: análise das redes entre instituições no Brasil. Revista de Administração Pública, v. 42, n. 6, p. 1041-1067, 2008b.

KEINERT, T. M. M. Os paradigmas de administração pública no Brasil (1900-1992). Revista de Administração de Empresas, v. 34, n. 3, p. 41-48, 1992.

KEINERT, T. M. M.; LAPORTA, C. B. A RAP e a evolução do campo de administração pública no Brasil (1965-92). Revista de Administração Pública, v. 28, n. 1, p. 5-17, 1994.

KELLOUGH, E. J.; PITTS, D.. W. Who contributes for Public Administration Review? Examining the characteristics of authors who submit manuscripts to the journal. Public Administration Review, v. 65, n. 1, p. 3-7, 2005.

KRIPPENDORFF, K. Content analysis. 2. ed. Thousand Oaks, CA: Sage, 2004.

KUHN, T. A estrutura das revoluções científicas. 9. ed. São Paulo: Perspectiva, 2009.

LAN, Z.; ANDERS, K. K. A paradigmatic view of contemporary public administration research: an empirical test. Administration \& Society, v. 32, n. 2, p. 138-165, 2000.

LYNN JR., L. E. A concise history of the field. In: FERLIE, E.; LYNN JR., L. E.; POLLITT, C. (Ed.). The Oxford handbook of public management. Oxford: Oxford University Press, 2005. p. 5-25.

MACHADO-DA-SILVA, C.; AMBONI, N.; CUNHA, V. Produção acadêmica em administração pública: período 1983-88. In: ENCONTRO NACIONAL
DA ASSOCIAÇÃO NACIONAL DOS PROGRAMAS DE PÓS-GRADUAÇÃO EM ADMINISTRAÇÃO, 18., 1989, Belo Horizonte. Anais... Belo Horizonte: Anpad, 1989.

MARTINS, P. E. M. Revisitando os clássicos da RAP. Revista de Administração Pública, v. 41, n. esp., p. 49-65, 2007.

MCCURDY, H. E.; CLEARY, R. E. Why can't we resolve the research issue in public administration? Public Administration Review, v. 44, n. 1, p. 49-55, 1984.

MEZZOMO, T. M.; LAPORTA, C. B. A RAP e a evolução do campo de administração pública no Brasil (1965-92). Revista de Administração Pública, v. 28, n. 1, p. 5-17, 1994.

MILLER, H. T.; JAJA. C. Some evidence of a pluralistic discipline: a narrative analysis of public administration symposia. Public Administration Review, v. 65, n. 6, p. 728-738, 2005.

PACHECO, R. Administração pública nas revistas especializadas: Brasil, 1995-2002. Revista de Administração de Empresas, v. 43, n. 4, p. 63-71, 2003.

PECI, A.; FORNAZIN, M. The knowledge-building process of public administration research: a comparative perspective between Brazil and North American contexts. International Review of Administrative Sciences, v. 83, n. 1, p. 99-119, 2017. Suplemento.

$\mathrm{PECl}$, A. et al. Paradigmas orientadores da pesquisa em administração pública no contexto brasileiro. In: ENCONTRO DA ASSOCIAÇÃO NACIONAL DE PROGRAMAS DE PÓS-GRADUAÇÃO EM ADMINISTRAÇÃO, 35., 2011, Rio de Janeiro. Anais... Rio de Janeiro: Anpad, 2011.

PERRY, J. L.; KRAEMER, K. L. Research methodology in the "Public Administration Review," 1975-1984. Public Administration Review, v. 46, n. 3, p. 215-226, 1986.

ROOSENBLOOM, D. Public administrative theory and the separation of powers. Public Administration Review, v. 43, n. 3, p. 219-227, 1983.

SOUZA, C. Pesquisa em administração pública no Brasil: uma agenda para o debate. Revista de Administração Pública, v. 32, n. 4, p. 43-61, 1998.

STALLINGS, R. A.; FERRIS, J. M. Public administration research: work in PAR, 1940-1984. Public Administration Review, v. 48, n. 1, p. $580-587,1988$.

STREIB, G.; SLOTKIN, B. J.; RIVERA, M. Public administration research from a practitioner perspective. Public Administration Review, v. 61 , n. 5, p. 515-525, 2001.

WHITE, J. D. Dissertations and publications in public administration. Public Administration Review, v. 46, n. 3, p. 227-234, 1986.

WRIGHT, B. E. Public administration as an interdisciplinary field: assessing its relationship with the fields of law, management, and political science. Public Administration Review, v. 71, n. 1, Jan-Feb., p. 96-101, 2011.

Alketa Peci

Doutora em administração e professora associada da Escola Brasileira de Administração Pública e de Empresas da Fundação Getulio Vargas. Editorachefe da Revista de Administração Pública (RAP). E-mail: alketa@fgv.br. 